\title{
Functionality of HDL: Antioxidation and Detoxifying Effects
}

\author{
Helen Karlsson, Anatol Kontush, and Richard W. James
}

\section{Contents}

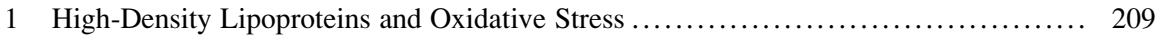

1.1 High-Density Lipoproteins: Antioxidative Function $\ldots \ldots \ldots \ldots \ldots \ldots \ldots \ldots \ldots \ldots$

1.2 Mechanisms of Protection ......................................... 210

1.3 Heterogeneity of Antioxidant Activity of HDL Particles .................... 213

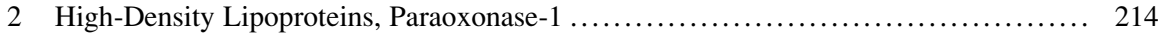

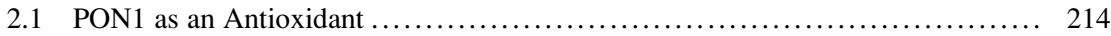

2.2 PON1 and Bacterial Pathogens ........................................ 216

3 High-Density Lipoproteins, Environmental Pathogens and Toxins ................. 217

3.1 Bacterial Pathogens ................................................... 217

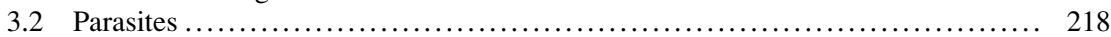

3.3 Hepatitis, Dengue and Other Viruses .................................... 219

3.4 Metal Oxides, Carbon Nanotubes and PLGA Nanoparticles ................. 219

3.5 PON1 and Organophosphates .................................... 220

3.6 Detoxification of Plasma and External Fluids .......................... 220

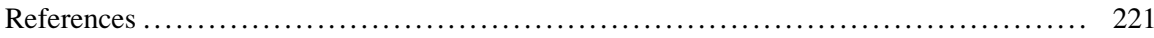

\section{H. Karlsson}

Occupational and Environmental Medicine, Heart Medical Centre, County Council of Ostergotland, Linkoping University, SE-58185 Linkoping, Sweden e-mail: helen.m.karlsson@liu.se

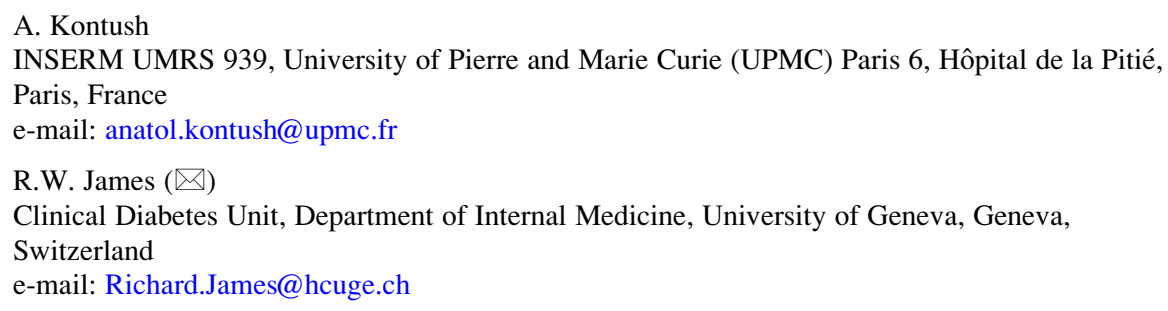

R.W. James $(\bowtie)$

Clinical Diabetes Unit, Department of Internal Medicine, University of Geneva, Geneva, Switzerland e-mail: Richard.James@hcuge.ch 


\section{Abstract \\ High-density lipoproteins (HDL) are complexes of multiple talents, some of which have only recently been recognised but all of which are under active investigation. Clinical interest initially arose from their amply demonstrated role in atherosclerotic disease with their consequent designation as a major cardio- vascular disease (CVD) risk factor. However, interest is no longer confined to vascular tissues, with the reports of impacts of the lipoprotein on pancreatic, renal and nervous tissues, amongst other possible targets. The ever-widening scope of HDL talents also encompasses environmental hazards, including infec- tious agents and environmental toxins. In almost all cases, HDL would appear to have a beneficial impact on health. It raises the intriguing question of whether these various talents emanate from a basic ancestral function to protect the cell. \\ The following chapter will illustrate and review our current understanding of some of the functions attributed to HDL. The first section will look at the antioxidative functions of HDL and possible mechanisms that are involved. The second section will focus specifically on paraoxonase-1 (PON1), which appears to bridge the divide between the two HDL functions discussed herein. This will lead into the final section dealing with HDL as a detoxifying agent protecting against exposure to environmental pathogens and other toxins.}

\section{Keywords}

HDL • Lipoproteins - Oxidative stress - Paraoxonase - Organophosphates • Bacterial pathogen $\bullet$ Antiviral activity $\bullet$ Nanoparticles $\bullet$ Bisphenol

\section{Abbreviations}

$\begin{array}{ll}\text { AAPH } & \text { Azo-initiator (2,2'-azobis-(2-amidinopropane) hydrochloride) } \\ \text { Apo } & \text { Apolipoprotein } \\ \text { BPA } & \text { Bisphenol A } \\ \text { CEOOH } & \text { Cholesteryl ester hydroperoxide } \\ \text { CETP } & \text { Cholesterol ester transfer protein } \\ \text { Cu } & \text { Copper } \\ \text { CVD } & \text { Cardiovascular disease } \\ \text { Cys } & \text { Cysteine } \\ \text { GSP } & \text { Glutathione peroxidase } \\ \text { Hb } & \text { Haemoglobin } \\ \text { Hbr } & \text { Haptoglobin-related protein } \\ \text { HBV } & \text { Hepatitis B virus } \\ \text { HDL } & \text { High-density lipoproteins } \\ \text { HETE } & \text { Hydroxy-eicosatetraenoic acid }\end{array}$




$\begin{array}{ll}\text { HODE } & \text { Hydroxyoctadecadienoic acid } \\ \text { HIV } & \text { Human immunodeficiency virus } \\ \text { HSL } & \text { Homoserine lactones } \\ \text { LCAT } & \text { Lecithin-cholesterol acyltransferase } \\ \text { LDL } & \text { Low-density lipoproteins } \\ \text { LOOH } & \text { Lipid hydroperoxide } \\ \text { LPS } & \text { Lipopolysaccharides } \\ \text { LSI } & \text { Liver somatic index } \\ \text { LTA } & \text { Lipoteichoic acid } \\ \text { Met } & \text { Methionine } \\ \text { MPO } & \text { Myeloperoxidase } \\ \text { NADPH } & \text { Nicotinamide adenine dinucleotide phosphate } \\ \text { NLF } & \text { Nasal lavage fluid } \\ \text { OP } & \text { Organophosphate } \\ \text { PAF-AH } & \text { Platelet-activating factor acetylhydrolase } \\ \text { PCB } & \text { Polychlorinated biphenyl } \\ \text { PLGA } & \text { Poly(lactic-co-glycolic acid) } \\ \text { PLOOH } & \text { Phospholipid hydroperoxide } \\ \text { PLTP } & \text { Phospholipid transfer protein } \\ \text { PON1 } & \text { Paraoxonase-1 } \\ \text { POP } & \text { Persistent organic pollutant } \\ \text { POPC } & \text { 1-palmitoyl-2-oleoyl-sn-glycero-3-phosphocholine } \\ \text { rHDL } & \text { Reconstituted HDL } \\ \text { SAA } & \text { Serum amyloid A } \\ \text { SRA } & \text { Serum resistance-associated } \\ \text { SR-BI } & \text { Scavenger receptor class B-I } \\ \text { TLF } & \text { Trypanolytic factor } \\ \text { TLR } & \text { Toll-like receptor } \\ \text { TNF } & \text { Tumour necrosis factor } \\ \text { Tyr } & \text { Tyrosine } \\ \text { VLDL } & \text { Low-density lipoproteins } \\ & \end{array}$

\section{$1 \quad$ High-Density Lipoproteins and Oxidative Stress}

The role of high-density lipoproteins (HDL) in the vascular system has been the primary focus of clinical interest. It arose from early studies of the influence of the lipoprotein on cholesterol metabolism and atherosclerosis. With increasing understanding of the complexity of the atherosclerotic process and involvement of other pathological mechanisms, attention has logically progressed to the impact of HDL on such mechanisms. One process is oxidative stress and there is now persuasive evidence that the lipoprotein can attenuate its consequences by a number of mechanisms. These are discussed in this section. 


\subsection{High-Density Lipoproteins: Antioxidative Function}

The response-to-retention hypothesis of atherosclerosis (Williams and Tabas 1995) postulates that cholesterol-rich lipoproteins, primarily low-density lipoproteins (LDL), are retained in the arterial wall and oxidatively modified under the action of resident cells (Stocker and Keaney 2004). Oxidation in the arterial intima results from local oxidative stress, which represents an imbalance between prooxidants and antioxidants in favour of the former. Cellular oxidative systems involved in vivo include myeloperoxidase (MPO), NADPH oxidase, nitric oxide synthase and lipoxygenase. They produce a variety of reactive chlorine, nitrogen and oxygen species in the form of one-electron (free radical) and two-electron oxidants (Gaut and Heinecke 2001).

HDL can protect LDL and other lipoproteins from oxidative stress induced by both one- and two-electron species. It can be observed in vitro on their co-incubation (Parthasarathy et al. 1990) and in vivo upon HDL supplementation (Klimov et al. 1993). One-electron oxidants modify both lipid and protein moieties of HDL with formation of lipid and protein radicals. It is followed by accumulation of primary oxidation products, initially lipid hydroperoxides $(\mathrm{LOOH})$, which in turn propagate further oxidation of HDL components to stable termination products (Stocker and Keaney 2004). HDL particles potently protect both lipid and protein moieties of LDL from free radical-induced oxidation, inhibiting accumulation of both primary and secondary oxidation products (Kontush and Chapman 2010). The following overview will focus on the impact of HDL on lipid hydroperoxides and other primary products of lipid peroxidation.

\subsection{Mechanisms of Protection}

HDL potently inhibits accumulation of LOOH in LDL. Removal of LOOH from LDL (or cells) represents a key step of HDL-mediated protection from oxidative damage induced by free radicals. Indeed, phospholipid hydroperoxides (PLOOHs) are rapidly transferred from LDL to HDL upon their co-incubation (Zerrad-Saadi et al. 2009). Addition of a hydroperoxyl group to a phospholipid or cholesteryl ester molecule strongly increases hydrophilicity. As a result, LOOH molecules are more surface active than their non-peroxidised counterparts (Nuchi et al. 2002). Their exposure to the aqueous phase at the HDL surface facilitates their removal from the lipoprotein. Transfer from LDL to HDL can occur directly between lipoprotein phospholipid monolayers, either spontaneously or mediated by lipid transfer proteins, including cholesterol ester transfer protein (CETP). The latter can accelerate the transfer of both cholesteryl ester hydroperoxides (CEOOHs) and PLOOHs (Christison et al. 1995). Thus, CETP can enhance the antioxidative activity of HDL towards LDL-derived LOOH. Removal of LOOH molecules from LDL can also be mediated by lipid-free apoA-I. As a consequence, HDL particles constitute a major transport vehicle of LOOH in human plasma, effectively functioning as a "sink" for oxidised lipids (Bowry et al. 1992). They can accumulate in the particle when its 
LOOH-inactivating capacity is overwhelmed. Furthermore, HDL represents a major plasma carrier of F2-isoprostanes, stable final products of lipid peroxidation (Proudfoot et al. 2009). The ability of HDL to remove LOOH from cell membranes of erythrocytes and astrocytes has also been reported (Ferretti et al. 2003; Klimov et al. 2001). Thus, the accumulation of oxidised lipids in HDL most probably results not only from their transfer from LDL but also from remnant triglyceride-rich lipoproteins and/or arterial wall cells, mediated in part by lipid transfer proteins (Christison et al. 1995). Subsequently, LOOHs and their corresponding hydroxides can be rapidly removed from HDL via scavenger receptor class B-I (SR-BI)mediated selective uptake by the liver (Christison et al. 1996). This pathway may significantly contribute to the removal of toxic, oxidised lipids from the body. As $\mathrm{CEOOH}$ are removed from the circulation more rapidly than the corresponding nonoxidised cholesteryl ester, addition of a hydroperoxyl group may accelerate cholesterol excretion. Following their transfer, HDL-associated LOOH are inactivated by reduction to the corresponding hydroxides in a two-electron redox reaction with HDL proteins (Garner et al. 1998; Zerrad-Saadi et al. 2009). ApoA-I plays a central role in redox inactivation of $\mathrm{LOOH}$ and may account for a large part of the antioxidation effects of the lipoprotein. ApoA-I Met residues 112 and 148 reduce $\mathrm{LOOH}$ to redox-inactive lipid hydroxides, thereby terminating chain reactions of lipid peroxidation (Garner et al. 1998; Zerrad-Saadi et al. 2009). Simulation by molecular dynamics shows interaction of Met112 and Met148 with Tyr115, creating a microenvironment unique to human apoA-I (Bashtovyy et al. 2011) that may be optimal for such redox reactions. LOOH is also inactivated by apoA-II, although to a lesser extent. The key role of apoA-I in the HDL-mediated protection of LDL from one-electron oxidants is supported by the observation that reconstituted HDL (rHDL) containing only purified apoA-I and phospholipid (POPC), but devoid of other protein and lipid components, are comparable to natural, small, dense HDL $3 b+3 c$ subfractions in their capacities to delay lipid peroxidation (Zerrad-Saadi et al. 2009). Concentrations of redox-active Met residues in apoA-I and of PLOOH suggest a 1:1 reaction stoichiometry (Garner et al. 1998; Zerrad-Saadi et al. 2009). HDL content of apoA-I and oxidative status of apoA-I Met residues are therefore important determinants of the capacity of HDL to inactivate $\mathrm{LOOH}$ and protect LDL from free radical-induced oxidation (ZerradSaadi et al. 2009). The redox reaction between HDL Met residues and LOOH is paralleled by the formation of oxidised forms of apoA-I and apoA-II which contain methionine sulfoxides. These methionine sulfoxide moieties can be reduced back to methionine by methionine sulfoxide reductases. In addition to Met, Cys residues may be important for the antioxidative properties of apoA-I, as demonstrated by the elevated inhibitory potency of the N74C mutant of apoA-I towards LDL oxidation (Zhang et al. 2010). His residues may also contribute to the apoA-I-mediated inhibition of $\mathrm{LOOH}$ accumulation in LDL, as a result of their metal-chelating properties (Nguyen et al. 2006). Indeed, transition metal ions are well-established catalysers of lipid peroxidation.

HDL particles contain other apolipoproteins that may contribute to inhibition of LOOH accumulation (Davidson et al. 2009; Ostos et al. 2001). Such antioxidative 
properties have been reported for apoA-IV (Ostos et al. 2001) and apoE (Miyata and Smith 1996). In addition, apoM displays antioxidative properties in transgenic mice where possible mechanisms may involve binding of oxidised phospholipids, including LOOH (Elsoe et al. 2012). Enzymatic components potentially contributing to antioxidative properties of HDL include paraoxonase-1 (PON1), platelet-activating factor acetylhydrolase (PAF-AH) and lecithin-cholesterol acyltransferase (LCAT), all of which have been proposed to hydrolyse oxidised phospholipids (Kontush and Chapman 2006). In addition, HDL carries glutathione peroxidase (GSPx) which can detoxify LOOH by reducing them to the corresponding hydroxides (Maddipati and Marnett 1987). Finally, the trypanosome lytic factor present in very high-density subpopulations of human HDL exhibits a peroxidase-like activity (Molina Portela et al. 2000) that may provide a minor contribution to LOOH-inactivating properties of HDL. With respect to PON1, PAF-AH and LCAT, these are weakly reactive towards LOOH (Goyal et al. 1997; Kriska et al. 2007; Teiber et al. 2004). HDL-associated PON1, which has been attributed a major antioxidant role in HDL (see Sect. 2.1), does not appear to contribute significantly to the inactivation of LDL-derived PLOOH (Garner et al. 1998; Zerrad-Saadi et al. 2009). Such activity that has been previously reported has been ascribed to the presence of detergents or unidentified proteins (Teiber et al. 2004). The major activity of PON1 is that of a calcium-dependent lactonase rather than a peroxidase (Khersonsky and Tawfik 2005); its affinity for $\mathrm{LOOH}$ is several orders of magnitude lower than its affinity for lactones (see Sect. 2.1 for further discussion of PON1). It is more probable that PAF-AH, rather than PON1, represents the hydrolase for PLOOH in HDL (Kriska et al. 2007). LCAT may equally hydrolyse PLOOH generated during lipoprotein oxidation (Goyal et al. 1997). In addition, it can delay LDL oxidation, acting as a chainbreaking antioxidant, most likely via its Cys residues (McPherson et al. 2007). Inhibition of LCAT does not, however, significantly influence HDL-mediated inactivation of LDL-derived PLOOH (Zerrad-Saadi et al. 2009), thereby indicating that the enzyme is at most a minor factor in PLOOH inactivation. Irrespective of the enzyme involved, PLOOH hydrolysis releases lysophosphatidylcholine and a free fatty acid hydroperoxide. Interestingly, PAF-AH is capable of hydrolysing PLOOH within oxidised LDL; in this case, free fatty acid hydroperoxides are transferred to HDL for subsequent two-electron reduction to corresponding hydroxides by apoA-I (Kotosai et al. 2013). As a result of elevated hydrophilicity, free fatty acid hydroperoxides, as compared to PLOOH and CEOOH (Kotosai et al. 2013), are preferentially transported to HDL and reduced to hydroxides.

In contrast to its effects on free radical-induced oxidation, HDL weakly protects LDL from oxidation by two-electron oxidants, such as hypochlorite, which mainly modify the protein moiety of LDL. Such antioxidative action appears largely unspecific, reflecting direct oxidant scavenging by HDL. A rare example of HDL-mediated protection from two-electron oxidants is inactivation by enzymes such as PAF-AH and/or PON1 with participation of apoA-I (Ahmed et al. 2001), of phospholipid core aldehydes generated upon HDL oxidation by peroxynitrite. 
Finally, HDL lipids can significantly modulate antioxidative activities displayed by the protein components. First, HDL carries small amounts of lipophilic antioxidants, primarily tocopherols, which may provide a minor contribution to its LOOH-inactivating properties (Bowry et al. 1992; Goulinet and Chapman 1997). Second, the rigidity of the phospholipid monolayer of HDL particles is a key negative modulator of PLOOH transfer efficiency from LDL and cell membranes (Vila et al. 2002; Zerrad-Saadi et al. 2009). The surface monolayer rigidity of HDL is primarily determined by the relative content of such lipids (sphingomyelin, free cholesterol, and saturated and monounsaturated fatty acids). Increasing the content of each rigidifies the surface monolayer of HDL particles at a given protein/lipid ratio (Zerrad-Saadi et al. 2009).

\subsection{Heterogeneity of Antioxidant Activity of HDL Particles}

Apolipoproteins, enzymes and lipids which determine the antioxidative activities of HDL are non-uniformly distributed across the spectrum of HDL subpopulations. ApoA-I, the major protein component of HDL participating in the reduction of LOOHs, is enriched relative to apoA-II in small, dense HDL3c and in large, less dense HDL2b as compared to HDL2a, 3a and $3 b$ subpopulations (Kontush et al. 2007). LCAT, PAF-AH, PON1 (Kontush et al. 2003) and apoA-IV (Bisgaier et al. 1985) are enriched in small, dense HDL. As a consequence, HDL particles are heterogeneous in their capacity to protect LDL from oxidative damage induced by one-electron oxidants. Small, dense, protein-rich HDL particles in particular potently protect LDL from mild oxidative stress induced by azo-initiator (2,2'-azobis-(2-amidinopropane) hydrochloride; AAPH) or $\mathrm{Cu}^{2+}$ (Kontush et al. 2003; Yoshikawa et al. 1997). It involves inactivation of LOOHs via a two-step mechanism with transfer of LOOHs to HDL (facilitated by enhanced fluidity of the HDL surface lipid monolayer) and subsequent reduction to redox-inactive hydroxides by Met residues of apoA-I (Christison et al. 1995; Garner et al. 1998; Zerrad-Saadi et al. 2009). Small, dense HDL 3 may be superior to large, less dense HDL 2 in terms of their capacity to remove oxidised lipids from other lipoproteins and cellular membranes. Structural defects in the packing of surface lipids, which allow insertion of exogenous molecules, become more pronounced with decreasing HDL particle size and may account for this property (Kumpula et al. 2008). Consistent with this possibility, small discoid rHDL complexes appear to remove negatively charged lipids from oxidised LDL to a greater degree than native, spherical HDL (Miyazaki et al. 1994). In addition, a diminished content of sphingomyelin and free cholesterol in small, dense HDL may result in an increased fluidity of the surface lipid monolayer, thereby facilitating incorporation of oxidised lipids of exogenous origin (Kontush and Chapman 2010).

Inactivation of oxidised lipid molecules following their transfer to HDL may also occur more rapidly in small, dense particles. First, reduction of LOOHs to hydroxides is more efficient in HDL3 as compared to HDL2 (Zerrad-Saadi et al. 2009). Relative enrichment of small, dense HDL in apoA-I may underlie 
this feature (Kontush et al. 2007). Moreover, the distinctly low lipid content of small, dense HDL can induce conformational changes in apoA-I relative to large, less dense HDL. It results in enhanced exposure to the aqueous phase, as reflected in modified reactivity towards monoclonal antibodies (Sparks et al. 1995), which might in turn facilitate the redox reaction between Met residues of apoA-I and LOOHs. Second, LOOH hydrolysis by HDL-associated hydrolytic enzymes appears to be predominantly associated with small, dense HDL3 (Kontush et al. 2003). Preferential localisation of enzymatic activities of PAF-AH within HDL3 is probably responsible for such association. Furthermore, enzymatic activities might be beneficially influenced by the lipidome of small, dense HDL3, which is distinct in displaying a low sphingomyelin to phosphatidylcholine ratio (Kontush et al. 2007). Indeed, sphingomyelin belongs to a class of structural lipids that exert a positive impact on surface rigidity and a negative impact on LCAT activity (Subbaiah and Liu 1993).

Finally, the unique proteome of HDL3c may have implications for its antioxidative activity. Several proteins, including apoJ, apoM, serum amyloid A4 (SAA4), apoD, apoL-1, PON1 and PON3 and phospholipid transfer protein (PLTP) occur predominantly in this subfraction (Davidson et al. 2009). Indeed, PLTP is present on HDL together with apoJ, apoL-I, apoD, apoA-I, apoA-II and several other proteins, suggesting a direct, functional interaction between them.

\section{$2 \quad$ High-Density Lipoproteins, Paraoxonase-1}

PON1 is an intriguing example of the functional flexibility of HDL components as it bridges the apparent divide between systemic oxidative stress and environmental toxicology. Originally identified as an enzyme neutralising environmental toxins, it progressed to an antioxidant role before revealing its capacity to combat pathogens: the functional complexity and versatility of HDL reflected in a single, peptide component. This section will focus on two aspects of PON1 function. It will expand on the antioxidant capacity of PON1 that was referred to in the preceeding section. Subsequently the ability of PON1 to limit bacterial virulence, notably with respect to Pseudomonas aeruginosa, will be addressed.

\subsection{PON1 as an Antioxidant}

Early, in vitro studies suggested that purified PON1 and HDL-associated PON1 could protect LDL from oxidation (Mackness et al. 2003), although these conclusions were questioned in subsequent reports (James 2006). However, studies from several animal models (James 2006) have provided much stronger support for the conclusion that PON1 protects against atherosclerotic disease by a process that involves reduction of oxidative stress. Thus PON1 knockout in mice was associated with a significant increase in the development of atherosclerotic lesions, whilst HDL from such mice were less able to protect LDL from oxidation (Shih 
et al. 1998, 2000). The latter was corrected by addition of purified PON1 to the HDL. Conversely, over-expression of PON1 protected against lesion development, with HDL showing a greater capacity to protect against oxidative stress (Tward et al. 2002). A consistent observation from these animal models is that PON1 activity is a negative correlate of markers of oxidative stress.

Studies in man are also consistent with a protective role of PON1, involving an impact on oxidative stress. In a number of disease states that increase risk of atherosclerotic disease and where increased oxidative stress is noted, PON1 serum activity is significantly reduced. These include diabetes, the metabolic syndrome, familial hypercholesterolaemia and renal dysfunction (Abbott et al. 1995; James 2006). Enzyme activity was also reduced in coronary disease patients, with the extent of coronary lesions correlating inversely with the PON1 activity (Graner et al. 2006). The relationship was independent of other risk factors. Other case-control investigations confirm that PON1 is a risk factor for coronary disease (Soran et al. 2009), although it is not a consistent observation (Troughton et al. 2008). Whilst the above studies focus on enzyme activity, there have also been a number of studies examining the relationship of PON1 coding region polymorphisms to coronary risk. The rationale is that a polymorphism at amino acid 192 gives rise to two isoforms with strikingly different activities towards paraoxon, one of the substrates used to analyse PON1 activity. Such studies have given somewhat equivocal results, as illustrated in a meta-analysis by Wheeler et al. (2004). However, this data should be interpreted with reserve as the range of activities is wide within each isoform. Moreover, the isoforms manifest much smaller differences in activities towards a second substrate, phenylacetate, frequently used to analyse PON1. It has led to suggestions that PON1 phenotype should be used to analyse the relationship of the enzyme to vascular risk (Jarvik et al. 2000).

More persuasive evidence of a role for PON1 in CVD comes from prospective studies. In the Caerphilly prospective study, serum PON1 activity was shown to be an independent determinant of future coronary events (Mackness et al. 2003). No measures of oxidative stress were undertaken. In two prospective studies, Hazen and colleagues (Bhattacharyya et al. 2008; Tang et al. 2012) firmly established PON1 as an independent risk factor for vascular disease, in both primary and secondary disease settings. They also analysed an impressive range of systemic indices of lipid oxidation (HETE, HODE, isoprostane) and showed a strong negative correlation between PON1 activity and serum concentrations of these markers.

These studies clearly suggest that it is the ability of PON1 to limit systemic oxidative stress and the generation of oxidised lipids that underlies its links to atherosclerotic disease. Alternative or complementary mechanisms by which PON1 could reduce risk have also been proposed (Aviram 2012; Rosenblat et al. 2013). The authors suggest that the enzyme can increase the free radical scavenging capacity of monocyte/macrophages and lower oxidative stress. The same group also proposed that PON1 increased the ability of HDL to remove cholesterol from macrophages (Rosenblat et al. 2011). The latter is thought to be an important step in reverse cholesterol transport. Data from the same study indicated that PON1 may 
increase the ability of HDL to prevent macrophage-mediated oxidation of LDL. In another study, the group proposed that PON1 could reduce the risk of diabetes, a potent CVD risk factor (Koren-Gluzer et al. 2011). The antioxidant function, acting via sulphydryl groups PON1, was suggested to play a role, but not enzyme activity.

Whilst there is persuasive evidence that PON1 prevents systemic lipid oxidation, how and what substrates it may act on are still unclear. As discussed above (Sect. 1.2), LOOH would appear to be poor substrates for the enzyme. Nevertheless, a feature of the PON1 knockout mice was an accumulation of LOOH in HDL (Shih et al. 1998; Tward et al. 2002). It is possible that short-chain oxidised phospholipids may be a better substrate for the enzyme. Increased lipoperoxides as well as lipid oxidation end products were also a feature of reduced PON1 activity in human studies (Bhattacharyya et al. 2008; Tang et al. 2012). One possible explanation may be furnished by a recent, intriguing proposal that PON1 can modulate the activity of myeloperoxidase (MPO). The latter is an important source of reactive oxygen species and is associated with HDL. Huang et al. (2013) reported that PON1 and MPO form a ternary complex with HDL. In this constellation, PON1 was able to modulate MPO activity (and conversely MPO inhibited PON1). Confirmation was obtained in vitro by showing that adding PON1 to active MPO significantly reduced lipid peroxidation by the latter.

At present, the question remains open as to how exactly PON1 functions, with possible explanations being prevention of ROS formation, curtailing propagation of ROS or hydrolysing oxidised lipids.

\subsection{PON1 and Bacterial Pathogens}

A major advance in our appreciation of the physiological relevance of PON1 was the demonstration that its principal enzyme activity is that of a lactonase (Khersonsky and Tawfik 2005). Indeed, lactonase activity would appear to be the initial, ancestral enzyme activity of the PON gene family. These observations considerably broadened the scope of HDL functions as lactonases are instrumental in neutralising bacterial virulence factors.

Pseudomonas aeruginosa is an opportunist bacterium and a common cause of disease in immunocompromised patients. It is also a major contributor to nosocomial infections. Bacterial virulence is governed by homoserine lactones (HSL) synthesised and secreted by the bacterium. They are central to the phenomenon of quorum sensing that allows communication between bacteria. The HSLs give a measure of bacterial density and when a threshold bacteria count is achieved, they activate gene programmes that greatly increase the rate of Pseudomonas infection (Juhas et al. 2005). The ability of the PON enzymes to hydrolyse the HSL interrupts bacterial communication and reduces virulence. Whilst the intracellular PON2 variant shows the strongest lactonase activity, PON1is also active towards HSL (Ozer et al. 2005) and is able to protect against Pseudomonas infection (Stoltz et al. 2008). Indeed, PON1 is the major source of HSL neutralising activity in serum (Teiber et al. 2008). 
Discovery of its role in combating bacterial infection and knowledge that the paraoxonases are a highly conserved gene family have led to suggestions that they may play a role in innate immunity (Shih and Lusis 2009).

\section{$3 \quad$ High-Density Lipoproteins, Environmental Pathogens and Toxins}

In recent studies, the molecular composition of the HDL particle has been assigned significant, functional importance (Besler et al. 2012), which is of particular relevance with respect to reported changes in HDL composition in disease. Interestingly, alterations in HDL composition have also been observed in man during endotoxemia (Levels et al. 2011) and in endotoxin-treated mice (Chiba et al. 2011). As suggested above, data indicate that HDL has an important role in neutralising and detoxifying invading pathogens to prevent systemic inflammatory responses or sepsis, which is the leading cause of death in intensive care units (ICUs) of highincome countries (Levels et al. 2011; Russell 2006). Concurrently, the interaction of HDL with viruses, parasites and environmental toxins has also been a focus of recent interest. This is reflected in reviews of the impact of gram-positive and gramnegative bacterial toxins in sepsis (Ramachandran 2013), the role of HDL in innate immunity (Feingold and Grunfeld 2011) and the immune system (Kaji 2013) and xenobiotic metabolism, disposition and regulation of receptors (Omiecinski et al. 2011) to which the reader is referred. In this chapter, the role(s) of HDL as a detoxifying agent during exposure to different environmental pathogens or toxins will be discussed.

\subsection{Bacterial Pathogens}

Multiple alterations in lipid and lipoprotein metabolism occur during the acute phase response. Within HDL, apoA-I, cholesterol and phospholipid levels decrease, as do certain enzyme activities, e.g. PON1 (Khovidhunkit et al. 2004), whilst free apoA-I (Cabana et al. 1997) and triglyceride levels increase (Cabana et al. 1996). As a consequence, reverse cholesterol transport decreases, accompanied by increased cholesterol delivery to immune cells. Such alterations initially protect the host from the harmful effects of invading pathogens but will contribute to atherogenesis if prolonged (Khovidhunkit et al. 2004).

A crucial factor in the detoxifying properties attributed to HDL is the ability to neutralise the invading pathogen. A number of human studies have shown that circulating lipoproteins, principally HDL, are able to bind lipopolysaccharides (LPS) from gram-negative bacteria as well as lipoteichoic acid (LTA) from grampositive bacteria (Khovidhunkit et al. 2004; Levels et al. 2003, 2011). Binding to HDL inhibits LPS interaction with cell surface toll-like receptor 4 (TLR-4) (Underhill and Ozinsky 2002) and LTA interaction with TLR-2 (Flo et al. 2000), receptors known to mediate inflammatory responses (macrophage activation, 
cytokine release). These neutralising effects of HDL have been confirmed in humans with low HDL levels who show a more robust inflammatory response to LPS administration (Birjmohun et al. 2007).

During the acute phase response, HDL protein and lipid compositions change (Khovidhunkit et al. 2004). Observations indicate that apoA-I can be replaced by the positive acute phase protein SAA (Artl et al. 2000). SAA is able to influence HDL-mediated cholesterol metabolism through its inhibitory effects on SR-BImediated selective cholesterol uptake (Cai et al. 2005). It has recently been suggested to facilitate the binding of HDL, isolated from mice injected with LPS, to vascular proteoglycans (Chiba et al. 2011). The relevance of these observations is important when taken together with the up to 1,000-fold increase in concentrations of plasma SAA during acute phase reactions such as inflammation or infection. In addition, several isoforms of SAA, still with unknown functions, have recently been detected in acute phase HDL (Levels et al. 2011).

The neutralising effects of HDL during LPS exposure are dependent on phospholipids as well as proteins. ApoA-I is suggested to be the major neutralising factor (Massamiri et al. 1997). Thus, direct interaction between LPS and the C-terminus of apoA-I can decrease TNF- $\alpha$ release from macrophages in vitro (Henning et al. 2011). The role of apoA-I as a neutralising agent is further strengthened by the beneficial effects of apoA-I on LPS-induced acute lung injury and endotoxemia, as shown in mice (Yan et al. 2006).

The HDL receptor, SR-BI, is highly expressed in hepatocytes and steroidproducing cells and has an important role regarding the fate of the neutralised pathogens. In mice, it is suggested to protect against endotoxemia through its roles in facilitating glucocorticoid production as well as hepatic clearance of LPS. In this respect, SR-BI has been suggested to mediate the binding and uptake of LPS as well as LTA (Vishnyakova et al. 2006). Additionally, an alternatively spliced variant, SR-BII, has been shown to bind directly a variety of bacteria suggesting a conserved role of these receptors in pattern recognition and innate immunity (Webb et al. 1998).

\subsection{Parasites}

Several species of African trypanosomes cause fatal disease in livestock, but most are unable to infect humans due to innate trypanolytic factors (TLFs). It has been shown that in human serum, TLFs consist of two minor HDL subfractions characterised by the presence of haptoglobin-related protein $(\mathrm{Hpr})$ and apoL-I (Vanhamme et al. 2003). The underlying mechanisms of TLFs action during parasite infection involve their endocytosis by trypanosomes where, subsequently, apoL-I forms membrane pores within the acidic lysosome resulting in ion dysregulation that leads to osmotic imbalance, parasite swelling and lysis (Molina-Portela Mdel et al. 2005). Endocytosis of apoL-I is facilitated by a complex formed by Hpr and haemoglobin that interacts with the haptoglobinhaemoglobin receptor on the trypanosome cell surface (Vanhollebeke 
et al. 2008). However, Trypanosoma brucei rhodesiense, carried by tsetse flies and causing sleeping sickness in man, is able to escape lysis by TLFs. It is achieved mainly by the expression of the serum resistance-associated (SRA) protein, which binds to and neutralises apoL-I (Vanhamme et al. 2003). It should be noted however that recent population-based observations, focused on individual variations in $\mathrm{Hpr}$, indicate that a more dynamic view of the relative roles of $\mathrm{Hpr}$ and $\mathrm{Hpr}-\mathrm{Hb}$ complexes needs to be considered for understanding innate immunity to African trypanosomes. Other pathogens including the newly discovered Plasmodium (Imrie et al. 2012) should possibly be considered.

\subsection{Hepatitis, Dengue and Other Viruses}

HDL account for part of the broad, non-specific antiviral activity in human serum (Singh et al. 1999). Thus, apoA-I was found to prevent cell penetration by inhibiting fusion of the herpes virus as well as the human immunodeficiency virus (HIV) (Srinivas et al. 1990). Interestingly, HIV infection has also been linked to dysfunctional HDL with reduced antioxidant properties, which may be associated to progression of subclinical atherosclerosis (Kelesidis et al. 2013). In addition, enhanced levels of human apoM, which is mainly associated with HDL, were observed during hepatitis B virus (HBV) infection and may reflect feedback suppression of HBV replication (Gu et al. 2011). Conversely, HDL may also promote virulence by facilitating virus entry via the SR-BI receptor. This was first demonstrated for the hepatitis $C$ viruses (Voisset et al. 2006) and recently extended to dengue viruses that directly associate with apoA-I of HDL (Li et al. 2013). It is perhaps unsurprising that SR-BI has recently been proposed as a therapeutic target that warrants further research, based on reports indicating its involvement in the capture and cross-presentation of antigens from viruses, bacteria and parasites.

\subsection{Metal Oxides, Carbon Nanotubes and PLGA Nanoparticles}

Nanotechnology is an emerging industry that involves the creation of new materials with a variety of useful functions. However, concerns are growing that some of them may have toxic effects. This has promoted interest in the role of HDL both as a neutralising agent and carrier of nanosize particles. Thus the biodistribution of nanoparticles is significantly influenced by their interaction with plasma proteins, notably HDL proteins apoA-I and apoE. These, amongst others, have been found to recognise and interact with carbon nanotubes, a number of metal oxides (Karlsson et al. 2012) and PLGA (poly(lactic-co-glycolic acid)) nanoparticles (Sempf et al. 2013) in in vitro plasma models. There are, as yet, no detailed studies confirming HDL neutralisation and clearance of engineered nanoparticles. However, the concept of incorporating lipophilic drugs assembled with apoA-I and phospholipids into soluble, HDL-like nanoparticles for drug delivery is presently 
widely explored (Marrache and Dhar 2013; Shin et al. 2013). They could serve a number of therapeutic purposes, for example, targeting tissues expressing high amounts of SR-BI, such as cancer cells (Marrache and Dhar 2013; Shin et al. 2013).

\subsection{PON1 and Organophosphates}

A crucial function of HDL-associated PON1, in addition to its potential antioxidant role, is neutralisation of toxic organophosphate (OP) derivatives. Such an activity was described in human serum many years ago (Aldridge 1953). The activity was attributed to the enzyme PON1, a name derived from the substrate paraoxon, initially employed in such studies. Its involvement in the detoxification of OPs has since been well documented, encompassing chlorpyrifos, oxon and diazoxon as well as nerve agents (Costa et al. 2013). Indeed, HDL-associated PON1 has been shown to be a key determinant in detoxification of OPs (Shih et al. 1998) in mouse models. Intriguingly, PON1 was shown to be associated with HDL at a time when its antioxidant activity was unknown (James 2006).

A growing area of research is the importance of PON1 in environment toxicology and its role in susceptibility to OP exposure. Serum concentrations of the enzyme, as well as certain polymorphisms affecting activity, appear important for risk prediction (Androutsopoulos et al. 2011; Costa et al. 2013). Consequently, children may be more sensitive to environmental OPs since they have reportedly lower PON1 levels than adults (Huen et al. 2009). Finally, its impact on environmental toxins, as well as its antioxidant function, has led to suggestions that PON1 is linked to neurological disorders (Androutsopoulos et al. 2011), an area that requires considerably more research.

\subsection{Detoxification of Plasma and External Fluids}

As discussed in previous sections, HDL and apo A-I have a role in recognition, neutralisation and elimination of xenobiotics. Thus, elevated levels of plasma apoA-I in female rats have been found after exposure to the plastic chemical bisphenol A (BPA) (Ronn et al. 2013). The molecular mechanisms behind the increase in apoA-I may reflect the effects of estrogens, although conflicting data have been reported (Teeguarden et al. 2013). It could also be related to apoA-I/ HDL-controlled clearance mechanisms that involve transport of xenobiotics to the liver. Interestingly, an increase in liver somatic index (LSI) accompanied the apoAI increase in the exposed rats, indicating less favourable metabolic alterations. Since the structure of BPA is very similar to a number of recently proposed apoA-I enhancing drugs (Du et al. 2012), it may be relevant to investigate these mechanisms further.

Another group of environmental contaminants, present at low levels in most living organisms, are persistent organic pollutants (POPs). Due to their hydrophobic character, they can be transported by lipoprotein particles. Interestingly, long-term 
effects of POPs in human plasma have recently been highlighted in a number of epidemiological studies (Lind et al. 2012). In a recent study of an exposed Swedish population, significantly higher concentrations of POPs were found amongst individuals with CVD or cancer compared to controls (Ljunggren et al. 2014). Principal component analyses showed that POP concentrations in HDL were more associated with CVD, whilst POP concentrations in LDL/VLDL were more associated with cancer. Interestingly, PON-1 activity was negatively correlated to the sum of polychlorinated biphenyls (PCBs), and covariation between decreased arylesterase activity, increased PCB concentrations and CVD was found.

To expand the knowledge regarding the role of HDL as detoxifier, it may be beneficial exploring external fluids. Lipids are present in human tears (Rantamaki et al. 2011), and apoA-I has been detected in nasal lavage fluid (NLF) (Ghafouri et al. 2002) and saliva (Ghafouri et al. 2003). Interestingly, in NLF, apoA-I was shown to increase in hairdressers after $20 \mathrm{~min}$ of exposure to persulphates (Karedal et al. 2010), whilst apoA-I in gingival crevicular fluid has been suggested to be a novel periodontal disease marker (Tsuchida et al. 2012). In addition, decreased levels of apoA-I have been reported in bronchio-alveolar lavage fluids of patients with idiopathic pulmonary fibrosis compared to healthy controls (Kim et al. 2010). Together with lipocalin, apoA-I has been suggested as a potential biomarker for chronic obstructive pulmonary disease (Nicholas et al. 2010). The origin of apoA-I in fluids of the airways has not been extensively studied, but trans-endothelial transport has been investigated (Ohnsorg et al. 2011). The presence, composition and possible function of apoA-I containing lipoprotein particles in external fluids remain to be investigated.

Acknowledgements RWJ gratefully acknowledges support received from the Swiss National Research Foundation, the Novartis Consumer Health Foundation and Unitec, University of Geneva. AK acknowledges financial support from the National Institute for Health and Medical Research (INSERM).

HK, AK and RWJ are members of the COST Action BM0904.

Open Access This chapter is distributed under the terms of the Creative Commons Attribution Noncommercial License, which permits any noncommercial use, distribution, and reproduction in any medium, provided the original author(s) and source are credited.

\section{References}

Abbott CA, Mackness MI, Kumar S, Boulton AJ, Durrington PN (1995) Serum paraoxonase activity, concentration, and phenotype distribution in diabetes mellitus and its relationship to serum lipids and lipoproteins. Arterioscler Thromb Vasc Biol 15(11):1812-1818

Ahmed Z, Ravandi A, Maguire GF, Emili A, Draganov D, La Du BN, Kuksis A, Connelly PW (2001) Apolipoprotein A-I promotes the formation of phosphatidylcholine core aldehydes that are hydrolyzed by paraoxonase (PON-1) during high density lipoprotein oxidation with a peroxynitrite donor. J Biol Chem 276(27):24473-24481

Aldridge WN (1953) Serum esterases. II. An enzyme hydrolysing diethyl p-nitrophenyl phosphate (E600) and its identity with the A-esterase of mammalian sera. Biochem J 53(1):117-124 
Androutsopoulos VP, Kanavouras K, Tsatsakis AM (2011) Role of paraoxonase 1 (PON1) in organophosphate metabolism: implications in neurodegenerative diseases. Toxicol Appl Pharmacol 256(3):418-424

Artl A, Marsche G, Lestavel S, Sattler W, Malle E (2000) Role of serum amyloid A during metabolism of acute-phase HDL by macrophages. Arterioscler Thromb Vasc Biol 20 (3):763-772

Aviram M (2012) Atherosclerosis: cell biology and lipoproteins - paraoxonases protect against atherosclerosis and diabetes development. Curr Opin Lipidol 23(2):169-171

Bashtovyy D, Jones MK, Anantharamaiah GM, Segrest JP (2011) Sequence conservation of apolipoprotein A-I affords novel insights into HDL structure-function. J Lipid Res 52 (3):435-450

Besler C, Luscher TF, Landmesser U (2012) Molecular mechanisms of vascular effects of highdensity lipoprotein: alterations in cardiovascular disease. EMBO Mol Med 4(4):251-268

Bhattacharyya T, Nicholls SJ, Topol EJ, Zhang R, Yang X, Schmitt D, Fu X, Shao M, Brennan DM, Ellis SG, Brennan ML, Allayee H, Lusis AJ, Hazen SL (2008) Relationship of paraoxonase 1 (PON1) gene polymorphisms and functional activity with systemic oxidative stress and cardiovascular risk. JAMA 299(11):1265-1276

Birjmohun RS, van Leuven SI, Levels JH, van't Veer C, Kuivenhoven JA, Meijers JC, Levi M, Kastelein JJ, van der Poll T, Stroes ES (2007) High-density lipoprotein attenuates inflammation and coagulation response on endotoxin challenge in humans. Arterioscler Thromb Vasc Biol 27(5):1153-1158

Bisgaier CL, Sachdev OP, Megna L, Glickman RM (1985) Distribution of apolipoprotein A-IV in human plasma. J Lipid Res 26(1):11-25

Bowry VW, Stanley KK, Stocker R (1992) High density lipoprotein is the major carrier of lipid hydroperoxides in human blood plasma from fasting donors. Proc Natl Acad Sci U S A 89 (21):10316-10320

Cabana VG, Lukens JR, Rice KS, Hawkins TJ, Getz GS (1996) HDL content and composition in acute phase response in three species: triglyceride enrichment of HDL a factor in its decrease. J Lipid Res 37(12):2662-2674

Cabana VG, Gidding SS, Getz GS, Chapman J, Shulman ST (1997) Serum amyloid A and high density lipoprotein participate in the acute phase response of Kawasaki disease. Pediatr Res 42 (5):651-655

Cai L, de Beer MC, de Beer FC, van der Westhuyzen DR (2005) Serum amyloid A is a ligand for scavenger receptor class B type I and inhibits high density lipoprotein binding and selective lipid uptake. J Biol Chem 280(4):2954-2961

Chiba T, Chang MY, Wang S, Wight TN, McMillen TS, Oram JF, Vaisar T, Heinecke JW, De Beer FC, De Beer MC, Chait A (2011) Serum amyloid A facilitates the binding of high-density lipoprotein from mice injected with lipopolysaccharide to vascular proteoglycans. Arterioscler Thromb Vasc Biol 31(6):1326-1332

Christison JK, Rye KA, Stocker R (1995) Exchange of oxidized cholesteryl linoleate between LDL and HDL mediated by cholesteryl ester transfer protein. J Lipid Res 36(9):2017-2026

Christison J, Karjalainen A, Brauman J, Bygrave F, Stocker R (1996) Rapid reduction and removal of HDL- but not LDL-associated cholesteryl ester hydroperoxides by rat liver perfused in situ. Biochem J 314(Pt 3):739-742

Costa LG, Giordano G, Cole TB, Marsillach J, Furlong CE (2013) Paraoxonase 1 (PON1) as a genetic determinant of susceptibility to organophosphate toxicity. Toxicology 307:115-122

Davidson WS, Silva RA, Chantepie S, Lagor WR, Chapman MJ, Kontush A (2009) Proteomic analysis of defined HDL subpopulations reveals particle-specific protein clusters: relevance to antioxidative function. Arterioscler Thromb Vasc Biol 29(6):870-876

Du Y, Yang Y, Jiang W, Wang L, Jia XJ, Si SY, Chen XF, Hong B (2012) Substituted benzamides containing azaspiro rings as upregulators of apolipoprotein A-I transcription. Molecules 17 
Elsoe S, Ahnstrom J, Christoffersen C, Hoofnagle AN, Plomgaard P, Heinecke JW, Binder CJ, Bjorkbacka H, Dahlback B, Nielsen LB (2012) Apolipoprotein M binds oxidized phospholipids and increases the antioxidant effect of HDL. Atherosclerosis 221(1):91-97

Feingold KR, Grunfeld C (2011) The role of HDL in innate immunity. J Lipid Res 52(1):1-3

Ferretti G, Bacchetti T, Moroni C, Vignini A, Curatola G (2003) Copper-induced oxidative damage on astrocytes: protective effect exerted by human high density lipoproteins. Biochim Biophys Acta 1635(1):48-54

Flo TH, Halaas O, Lien E, Ryan L, Teti G, Golenbock DT, Sundan A, Espevik T (2000) Human toll-like receptor 2 mediates monocyte activation by Listeria monocytogenes, but not by group B streptococci or lipopolysaccharide. J Immunol 164(4):2064-2069

Garner B, Waldeck AR, Witting PK, Rye KA, Stocker R (1998) Oxidation of high density lipoproteins. II. Evidence for direct reduction of lipid hydroperoxides by methionine residues of apolipoproteins AI and AII. J Biol Chem 273(11):6088-6095

Gaut JP, Heinecke JW (2001) Mechanisms for oxidizing low-density lipoprotein. Insights from patterns of oxidation products in the artery wall and from mouse models of atherosclerosis. Trends Cardiovasc Med 11(3-4):103-112. doi:10.1016/S1050-1738(01)00101-3

Ghafouri B, Stahlbom B, Tagesson C, Lindahl M (2002) Newly identified proteins in human nasal lavage fluid from non-smokers and smokers using two-dimensional gel electrophoresis and peptide mass fingerprinting. Proteomics 2(1):112-120

Ghafouri B, Tagesson C, Lindahl M (2003) Mapping of proteins in human saliva using two-dimensional gel electrophoresis and peptide mass fingerprinting. Proteomics 3 (6): 1003-1015

Goulinet S, Chapman MJ (1997) Plasma LDL and HDL subspecies are heterogenous in particle content of tocopherols and oxygenated and hydrocarbon carotenoids. Relevance to oxidative resistance and atherogenesis. Arterioscler Thromb Vasc Biol 17(4):786-796

Goyal J, Wang K, Liu M, Subbaiah PV (1997) Novel function of lecithin-cholesterol acyltransferase. Hydrolysis of oxidized polar phospholipids generated during lipoprotein oxidation. J Biol Chem 272(26):16231-16239

Graner M, James RW, Kahri J, Nieminen MS, Syvanne M, Taskinen MR (2006) Association of paraoxonase-1 activity and concentration with angiographic severity and extent of coronary artery disease. J Am Coll Cardiol 47(12):2429-2435

Gu JG, Zhu CL, Cheng DZ, Xie Y, Liu F, Zhou X (2011) Enchanced levels of apolipoprotein M during HBV infection feedback suppresses HBV replication. Lipids Health Dis 10:154

Henning MF, Herlax V, Bakas L (2011) Contribution of the C-terminal end of apolipoprotein AI to neutralization of lipopolysaccharide endotoxic effect. Innate Immun 17(3):327-337

Huang Y, Wu Z, Riwanto M, Gao S, Levison BS, Gu X, Fu X, Wagner MA, Besler C, Gerstenecker G, Zhang R, Li XM, DiDonato AJ, Gogonea V, Tang WH, Smith JD, Plow EF, Fox PL, Shih DM, Lusis AJ, Fisher EA, DiDonato JA, Landmesser U, Hazen SL (2013) Myeloperoxidase, paraoxonase-1, and HDL form a functional ternary complex. J Clin Invest 123(9):3815-3828

Huen K, Harley K, Brooks J, Hubbard A, Bradman A, Eskenazi B, Holland N (2009) Developmental changes in PON1 enzyme activity in young children and effects of PON1 polymorphisms. Environ Health Perspect 117(10):1632-1638

Imrie HJ, Fowkes FJ, Migot-Nabias F, Luty AJ, Deloron P, Hajduk SL, Day KP (2012) Individual variation in levels of haptoglobin-related protein in children from Gabon. PLoS ONE 7(11): e49816

James RW (2006) A long and winding road: defining the biological role and clinical importance of paraoxonases. Clin Chem Lab Med 44(9):1052-1059. doi:10.1515/CCLM.2006.207

Jarvik GP, Rozek LS, Brophy VH, Hatsukami TS, Richter RJ, Schellenberg GD, Furlong CE (2000) Paraoxonase (PON1) phenotype is a better predictor of vascular disease than is PON1 (192) or PON1(55) genotype. Arterioscler Thromb Vasc Biol 20:2441-2447

Juhas M, Eberl L, Tummler B (2005) Quorum sensing: the power of cooperation in the world of Pseudomonas. Environ Microbiol 7(4):459-471 
Kaji H (2013) High-density lipoproteins and the immune system. J Lipids 2013:684903

Karedal MH, Mortstedt H, Jeppsson MC, Kronholm Diab K, Nielsen J, Jonsson BA, Lindh CH (2010) Time-dependent proteomic iTRAQ analysis of nasal lavage of hairdressers challenged by persulfate. J Proteome Res 9(11):5620-5628

Karlsson H, Ljunggren S, Ahrén M, Ghafouri B, Uvdahl K, Lindahl M, Ljungman A (2012) Two-dimensional gel electrophoresis and mass spectrometry in studies of nanoparticle-protein interactions. In: Magdeldin S (ed) Gel glectrophoresis - advanced techniques. In Tech, Rijeka

Kelesidis T, Yang OO, Kendall MA, Hodis HN, Currier JS (2013) Dysfunctional HDL and progression of atherosclerosis in HIV-1-infected and -uninfected adults. Lipids Health Dis $12: 23$

Khersonsky O, Tawfik DS (2005) Structure-reactivity studies of serum paraoxonase PON1 suggest that its native activity is lactonase. Biochemistry 44(16):6371-6382

Khovidhunkit W, Kim MS, Memon RA, Shigenaga JK, Moser AH, Feingold KR, Grunfeld C (2004) Effects of infection and inflammation on lipid and lipoprotein metabolism: mechanisms and consequences to the host. J Lipid Res 45(7):1169-1196

Kim TH, Lee YH, Kim KH, Lee SH, Cha JY, Shin EK, Jung S, Jang AS, Park SW, Uh ST, Kim YH, Park JS, Sin HG, Youm W, Koh ES, Cho SY, Paik YK, Rhim TY, Park CS (2010) Role of lung apolipoprotein A-I in idiopathic pulmonary fibrosis: antiinflammatory and antifibrotic effect on experimental lung injury and fibrosis. Am J Respir Crit Care Med 182(5):633-642

Klimov AN, Gurevich VS, Nikiforova AA, Shatilina LV, Kuzmin AA, Plavinsky SL, Teryukova NP (1993) Antioxidative activity of high density lipoproteins in vivo. Atherosclerosis 100 (1):13-18

Klimov AN, Kozhevnikova KA, Kuzmin AA, Kuznetsov AS, Belova EV (2001) On the ability of high density lipoproteins to remove phospholipid peroxidation products from erythrocyte membranes. Biochemistry (Mosc) 66(3):300-304

Kontush A, Chapman MJ (2006) Functionally defective high-density lipoprotein: a new therapeutic target at the crossroads of dyslipidemia, inflammation, and atherosclerosis. Pharmacol Rev 58(3):342-374

Kontush A, Chapman MJ (2010) Antiatherogenic function of HDL particle subpopulations: focus on antioxidative activities. Curr Opin Lipidol 21(4):312-318

Kontush A, Chantepie S, Chapman MJ (2003) Small, dense HDL particles exert potent protection of atherogenic LDL against oxidative stress. Arterioscler Thromb Vasc Biol 23(10):1881-1888

Kontush A, Therond P, Zerrad A, Couturier M, Negre-Salvayre A, de Souza JA, Chantepie S, Chapman MJ (2007) Preferential sphingosine-1-phosphate enrichment and sphingomyelin depletion are key features of small dense HDL3 particles: relevance to antiapoptotic and antioxidative activities. Arterioscler Thromb Vasc Biol 27(8):1843-1849

Koren-Gluzer M, Aviram M, Meilin E, Hayek T (2011) The antioxidant HDL-associated paraoxonase-1 (PON1) attenuates diabetes development and stimulates beta-cell insulin release. Atherosclerosis 219(2):510-518

Kotosai M, Shimada S, Kanda M, Matsuda N, Sekido K, Shimizu Y, Tokumura A, Nakamura T, Murota K, Kawai Y, Terao J (2013) Plasma HDL reduces nonesterified fatty acid hydroperoxides originating from oxidized LDL: a mechanism for its antioxidant ability. Lipids 48(6):569-578

Kriska T, Marathe GK, Schmidt JC, McIntyre TM, Girotti AW (2007) Phospholipase action of platelet-activating factor acetylhydrolase, but not paraoxonase-1, on long fatty acyl chain phospholipid hydroperoxides. J Biol Chem 282(1):100-108

Kumpula LS, Kumpula JM, Taskinen MR, Jauhiainen M, Kaski K, Ala-Korpela M (2008) Reconsideration of hydrophobic lipid distributions in lipoprotein particles. Chem Phys Lipids 155(1):57-62

Levels JH, Abraham PR, van Barreveld EP, Meijers JC, van Deventer SJ (2003) Distribution and kinetics of lipoprotein-bound lipoteichoic acid. Infect Immun 71(6):3280-3284 
Levels JH, Geurts P, Karlsson H, Maree R, Ljunggren S, Fornander L, Wehenkel L, Lindahl M, Stroes ES, Kuivenhoven JA, Meijers JC (2011) High-density lipoprotein proteome dynamics in human endotoxemia. Proteome Sci 9(1):34

Li Y, Kakinami C, Li Q, Yang B, Li H (2013) Human apolipoprotein A-I is associated with dengue virus and enhances virus infection through SR-BI. PLoS ONE 8(7):e70390

Lind PM, van Bavel B, Salihovic S, Lind L (2012) Circulating levels of persistent organic pollutants (POPs) and carotid atherosclerosis in the elderly. Environ Health Perspect 120 (1):38-43

Ljunggren S, Helmfrid I, Salihovic S, van Bavel B, Wingren G, Lindahl M, Karlsson H (2014) Persistent organic pollutants distribution in lipoprotein fractions in relation to cardiovascular disease and cancer. Environ Int 65:93-99

Mackness B, Durrington P, McElduff P, Yarnell J, Azam N, Watt M, Mackness M (2003) Low paraoxonase activity predicts coronary events in the Caerphilly Prospective Study. Circulation 107(22):2775-2779

Maddipati KR, Marnett LJ (1987) Characterization of the major hydroperoxide-reducing activity of human plasma. Purification and properties of a selenium-dependent glutathione peroxidase. J Biol Chem 262(36):17398-17403

Marrache S, Dhar S (2013) Biodegradable synthetic high-density lipoprotein nanoparticles for atherosclerosis. Proc Natl Acad Sci U S A 110(23):9445-9450

Massamiri T, Tobias PS, Curtiss LK (1997) Structural determinants for the interaction of lipopolysaccharide binding protein with purified high density lipoproteins: role of apolipoprotein A-I. J Lipid Res 38(3):516-525

McPherson PA, Young IS, McEneny J (2007) A dual role for lecithin:cholesterol acyltransferase (EC 2.3.1.43) in lipoprotein oxidation. Free Radic Biol Med 43(11):1484-1493

Miyata M, Smith JD (1996) Apolipoprotein E allele-specific antioxidant activity and effects on cytotoxicity by oxidative insults and beta-amyloid peptides. Nat Genet 14(1):55-61

Miyazaki A, Sakai M, Suginohara Y, Hakamata H, Sakamoto Y, Morikawa W, Horiuchi S (1994) Acetylated low density lipoprotein reduces its ligand activity for the scavenger receptor after interaction with reconstituted high density lipoprotein. J Biol Chem 269(7):5264-5269

Molina Portela MP, Raper J, Tomlinson S (2000) An investigation into the mechanism of trypanosome lysis by human serum factors. Mol Biochem Parasitol 110(2):273-282

Molina-Portela Mdel P, Lugli EB, Recio-Pinto E, Raper J (2005) Trypanosome lytic factor, a subclass of high-density lipoprotein, forms cation-selective pores in membranes. Mol Biochem Parasitol 144(2):218-226

Nguyen SD, Jeong TS, Sok DE (2006) Apolipoprotein A-I-mimetic peptides with antioxidant actions. Arch Biochem Biophys 451(1):34-42

Nicholas BL, Skipp P, Barton S, Singh D, Bagmane D, Mould R, Angco G, Ward J, GuhaNiyogi B, Wilson S, Howarth P, Davies DE, Rennard S, O'Connor CD, Djukanovic R (2010) Identification of lipocalin and apolipoprotein A1 as biomarkers of chronic obstructive pulmonary disease. Am J Respir Crit Care Med 181(10):1049-1060

Nuchi CD, Hernandez P, McClements DJ, Decker EA (2002) Ability of lipid hydroperoxides to partition into surfactant micelles and alter lipid oxidation rates in emulsions. J Agric Food Chem 50(19):5445-5449

Ohnsorg PM, Rohrer L, Perisa D, Kateifides A, Chroni A, Kardassis D, Zannis VI, von Eckardstein A (2011) Carboxyl terminus of apolipoprotein A-I (ApoA-I) is necessary for the transport of lipid-free ApoA-I but not prelipidated ApoA-I particles through aortic endothelial cells. J Biol Chem 286(10):7744-7754

Omiecinski CJ, Vanden Heuvel JP, Perdew GH, Peters JM (2011) Xenobiotic metabolism, disposition, and regulation by receptors: from biochemical phenomenon to predictors of major toxicities. Toxicol Sci 120(Suppl 1):S49-S75

Ostos MA, Conconi M, Vergnes L, Baroukh N, Ribalta J, Girona J, Caillaud JM, Ochoa A, Zakin MM (2001) Antioxidative and antiatherosclerotic effects of human apolipoprotein A-IV in apolipoprotein E-deficient mice. Arterioscler Thromb Vasc Biol 21(6):1023-1028 
Ozer EA, Pezzulo A, Shih DM, Chun C, Furlong C, Lusis AJ, Greenberg EP, Zabner J (2005) Human and murine paraoxonase 1 are host modulators of Pseudomonas aeruginosa quorumsensing. FEMS Microbiol Lett 253(1):29-37

Parthasarathy S, Barnett J, Fong LG (1990) High-density lipoprotein inhibits the oxidative modification of low-density lipoprotein. Biochim Biophys Acta 1044(2):275-283

Proudfoot JM, Barden AE, Loke WM, Croft KD, Puddey IB, Mori TA (2009) HDL is the major lipoprotein carrier of plasma F2-isoprostanes. J Lipid Res 50(4):716-722

Ramachandran G (2013) Gram-positive and gram-negative bacterial toxins in sepsis: a brief review. Virulence 5(1)

Rantamaki AH, Seppanen-Laakso T, Oresic M, Jauhiainen M, Holopainen JM (2011) Human tear fluid lipidome: from composition to function. PLoS ONE 6(5):e19553

Ronn M, Lind PM, Karlsson H, Cvek K, Berglund J, Malmberg F, Orberg J, Lind L, Ortiz-Nieto F, Kullberg J (2013) Quantification of total and visceral adipose tissue in fructose-fed rats using water-fat separated single echo MRI. Obesity (Silver Spring) 21(9):E388-E395

Rosenblat M, Volkova N, Aviram M (2011) Injection of paraoxonase 1 (PON1) to mice stimulates their HDL and macrophage antiatherogenicity. Biofactors 37(6):462-467

Rosenblat M, Elias A, Volkova N, Aviram M (2013) Monocyte-macrophage membrane possesses free radicals scavenging activity: stimulation by polyphenols or by paraoxonase 1 (PON1). Free Radic Res 47(4):257-267

Russell JA (2006) Management of sepsis. N Engl J Med 355(16):1699-1713

Sempf K, Arrey T, Gelperina S, Schorge T, Meyer B, Karas M, Kreuter J (2013) Adsorption of plasma proteins on uncoated PLGA nanoparticles. Eur J Pharm Biopharm 85(1):53-60

Shih DM, Lusis AJ (2009) The roles of PON1 and PON2 in cardiovascular disease and innate immunity. Curr Opin Lipidol 20(4):288-292

Shih DM, Gu L, Xia YR, Navab M, Li WF, Hama S, Castellani LW, Furlong CE, Costa LG, Fogelman AM, Lusis AJ (1998) Mice lacking serum paraoxonase are susceptible to organophosphate toxicity and atherosclerosis. Nature 394(6690):284-287

Shih DM, Xia YR, Wang XP, Miller E, Castellani LW, Subbanagounder G, Cheroutre H, Faull KF, Berliner JA, Witztum JL, Lusis AJ (2000) Combined serum paraoxonase knockout/apolipoprotein E knockout mice exhibit increased lipoprotein oxidation and atherosclerosis. J Biol Chem 275(23):17527-17535

Shin JY, Yang Y, Heo P, Lee JC, Kong B, Cho JY, Yoon K, Shin CS, Seo JH, Kim SG, Kweon DH (2013) pH-responsive high-density lipoprotein-like nanoparticles to release paclitaxel at acidic $\mathrm{pH}$ in cancer chemotherapy. Int J Nanomed 7:2805-2816

Singh IP, Chopra AK, Coppenhaver DH, Ananatharamaiah GM, Baron S (1999) Lipoproteins account for part of the broad non-specific antiviral activity of human serum. Antiviral Res 42 (3):211-218

Soran H, Younis NN, Charlton-Menys V, Durrington P (2009) Variation in paraoxonase-1 activity and atherosclerosis. Curr Opin Lipidol 20(4):265-274

Sparks DL, Davidson WS, Lund-Katz S, Phillips MC (1995) Effects of the neutral lipid content of high density lipoprotein on apolipoprotein A-I structure and particle stability. J Biol Chem 270 (45):26910-26917

Srinivas RV, Birkedal B, Owens RJ, Anantharamaiah GM, Segrest JP, Compans RW (1990) Antiviral effects of apolipoprotein A-I and its synthetic amphipathic peptide analogs. Virology 176(1):48-57

Stocker R, Keaney JF Jr (2004) Role of oxidative modifications in atherosclerosis. Physiol Rev 84 (4):1381-1478

Stoltz DA, Ozer EA, Taft PJ, Barry M, Liu L, Kiss PJ, Moninger TO, Parsek MR, Zabner J (2008) Drosophila are protected from Pseudomonas aeruginosa lethality by transgenic expression of paraoxonase-1. J Clin Invest 118(9):3123-3131

Subbaiah PV, Liu M (1993) Role of sphingomyelin in the regulation of cholesterol esterification in the plasma lipoproteins. Inhibition of lecithin-cholesterol acyltransferase reaction. J Biol Chem 268(27):20156-20163 
Tang WH, Hartiala J, Fan Y, Wu Y, Stewart AF, Erdmann J, Kathiresan S, Roberts R, McPherson R, Allayee H, Hazen SL (2012) Clinical and genetic association of serum paraoxonase and arylesterase activities with cardiovascular risk. Arterioscler Thromb Vasc Biol 32(11):2803-2812

Teeguarden J, Hanson-Drury S, Fisher JW, Doerge DR (2013) Are typical human serum BPA concentrations measurable and sufficient to be estrogenic in the general population? Food Chem Toxicol 62:949-963

Teiber JF, Draganov DI, La Du BN (2004) Purified human serum PON1 does not protect LDL against oxidation in the in vitro assays initiated with copper or AAPH. J Lipid Res 45 (12):2260-2268

Teiber JF, Horke S, Haines DC, Chowdhary PK, Xiao J, Kramer GL, Haley RW, Draganov DI (2008) Dominant role of paraoxonases in inactivation of the Pseudomonas aeruginosa quorum-sensing signal $\mathrm{N}$-(3-oxododecanoyl)-L-homoserine lactone. Infect Immun 76 (6):2512-2519

Troughton JA, Woodside JV, Yarnell JW, Arveiler D, Amouyel P, Ferrieres J, Ducimetiere P, Patterson CC, Luc G (2008) Paraoxonase activity and coronary heart disease risk in healthy middle-aged males: the PRIME study. Atherosclerosis 197(2):556-563

Tsuchida S, Satoh M, Umemura H, Sogawa K, Kawashima Y, Kado S, Sawai S, Nishimura M, Kodera Y, Matsushita K, Nomura F (2012) Proteomic analysis of gingival crevicular fluid for discovery of novel periodontal disease markers. Proteomics 12(13):2190-2202

Tward A, Xia YR, Wang XP, Shi YS, Park C, Castellani LW, Lusis AJ, Shih DM (2002) Decreased atherosclerotic lesion formation in human serum paraoxonase transgenic mice. Circulation 106(4):484-490

Underhill DM, Ozinsky A (2002) Toll-like receptors: key mediators of microbe detection. Curr Opin Immunol 14(1):103-110

Vanhamme L, Paturiaux-Hanocq F, Poelvoorde P, Nolan DP, Lins L, Van Den Abbeele J, Pays A, Tebabi P, Van Xong H, Jacquet A, Moguilevsky N, Dieu M, Kane JP, De Baetselier P, Brasseur R, Pays E (2003) Apolipoprotein L-I is the trypanosome lytic factor of human serum. Nature 422(6927):83-87

Vanhollebeke B, De Muylder G, Nielsen MJ, Pays A, Tebabi P, Dieu M, Raes M, Moestrup SK, Pays E (2008) A haptoglobin-hemoglobin receptor conveys innate immunity to Trypanosoma brucei in humans. Science 320(5876):677-681

Vila A, Korytowski W, Girotti AW (2002) Spontaneous transfer of phospholipid and cholesterol hydroperoxides between cell membranes and low-density lipoprotein: assessment of reaction kinetics and prooxidant effects. Biochemistry 41(46):13705-13716

Vishnyakova TG, Kurlander R, Bocharov AV, Baranova IN, Chen Z, Abu-Asab MS, Tsokos M, Malide D, Basso F, Remaley A, Csako G, Eggerman TL, Patterson AP (2006) CLA-1 and its splicing variant CLA-2 mediate bacterial adhesion and cytosolic bacterial invasion in mammalian cells. Proc Natl Acad Sci U S A 103(45):16888-16893

Voisset C, Op de Beeck A, Horellou P, Dreux M, Gustot T, Duverlie G, Cosset FL, Vu-Dac N, Dubuisson J (2006) High-density lipoproteins reduce the neutralizing effect of hepatitis C virus (HCV)-infected patient antibodies by promoting HCV entry. J Gen Virol 87(Pt 9):2577-2581

Webb NR, Connell PM, Graf GA, Smart EJ, de Villiers WJ, de Beer FC, van der Westhuyzen DR (1998) SR-BII, an isoform of the scavenger receptor BI containing an alternate cytoplasmic tail, mediates lipid transfer between high density lipoprotein and cells. J Biol Chem 273 (24):15241-15248

Wheeler JG, Keavney BD, Watkins H, Collins R, Danesh J (2004) Four paraoxonase gene polymorphisms in 11212 cases of coronary heart disease and 12786 controls: meta-analysis of 43 studies. Lancet 363(9410):689-695

Williams KJ, Tabas I (1995) The response-to-retention hypothesis of early atherogenesis. Arterioscler Thromb Vasc Biol 15(5):551-561

Yan YJ, Li Y, Lou B, Wu MP (2006) Beneficial effects of ApoA-I on LPS-induced acute lung injury and endotoxemia in mice. Life Sci 79(2):210-215 
Yoshikawa M, Sakuma N, Hibino T, Sato T, Fujinami T (1997) HDL3 exerts more powerful antioxidative, protective effects against copper-catalyzed LDL oxidation than HDL2. Clin Biochem 30(3):221-225

Zerrad-Saadi A, Therond P, Chantepie S, Couturier M, Rye KA, Chapman MJ, Kontush A (2009) HDL3-mediated inactivation of LDL-associated phospholipid hydroperoxides is determined by the redox status of apolipoprotein A-I and HDL particle surface lipid rigidity: relevance to inflammation and atherogenesis. Arterioscler Thromb Vasc Biol 29(12):2169-2175

Zhang X, Zhu X, Chen B (2010) Inhibition of collar-induced carotid atherosclerosis by recombinant apoA-I cysteine mutants in apoE-deficient mice. J Lipid Res 51(12):3434-3442 